\title{
Magnetite Thin Film on Mild Steel Formed by Hydrothermal Electrolysis for Corrosion Prevention
}

Siti Machmudah ${ }^{1, *}$, Rizka Zulhijah ${ }^{1}$, Wahyudiono ${ }^{2}$, Heru Setyawan ${ }^{1}$, Hideki Kanda ${ }^{3}$ and Motonobu Goto ${ }^{3, *}$

${ }^{1}$ Department of Chemical Engineering, Se puluh Nopember Institute of Technology, Kampus ITS, Keputih Sukolilo, Surabaya 60111, Indonesia

${ }^{2}$ Department of Chemical Engineering, Surabaya of University, Raya Kalirungkut, Surabaya 60293, Indonesia

${ }^{3}$ Department of Chemical Engineering, Nagoya University, Furo-cho, Chikusa-ku, Nagoya 464-8603, Japan

*Corresponding author. E-mail: machmudah@chem-eng.its.ac.id; mgoto@nuce.nagoya-u.ac.jp. Tel: +62-31-5946240; +81-52-789-3991. Fax: +62-31-5999282; +81-52-789-3991.

Footnote

Siti Machmudah ${ }^{1, *}$, Rizka Zulhijah ${ }^{1}$, Wahyudiono ${ }^{2}$, Heru Setyawan ${ }^{1}$, Hideki Kanda $^{3}$ and Motonobu Goto ${ }^{3, *}$

${ }^{1}$ Department of Chemical Engineering, Se puluh Nopember Institute of Technology, Kampus ITS, Keputih Sukolilo, Surabaya 60111, Indonesia

${ }^{2}$ Department of Chemical Engineering, Surabaya of University, Raya Kalirungkut, Surabaya 60293, Indonesia

${ }^{3}$ Department of Chemical Engineering, Nagoya University, Furo-cho, Chikusa-ku, Nagoya 464-8603, Japan 


\begin{abstract}
Magnetite film was successfully prepared on the mild steel surface in alkaline environment by hydrothermal electrolysis treatment. The principle of hydrothermal electrolysis is applying current directly to electrolyte solution at hydrothermal conditions. The anodizing of mild steel was conducted at temperatures of $100-200{ }^{\circ} \mathrm{C}$ and applied current densities of $0.1-0.4$ $\mathrm{A} / \mathrm{cm}^{2}$ for 5-60 min reaction time with sodium hydroxide $(\mathrm{NaOH})$ as an electrolyte solution (5-15\%). Magnetite film on the mild steel surface was characterized by X-ray diffraction (XRD), field emission scanning electron microscopy (FE-SEM), and cyclic voltammetry. The patterns of XRD showed that magnetite was formed dominantly in the surface of mild steel with black color. Cyclic voltammetry analys is showed that the magnetite films produced on the mild steel surface could prevent or minimize the corrosion on its surface.
\end{abstract}

Keywords: Magnetite; Anodizing; Blackening; Mild steel; Hydrothermal electrolysis

\title{
1. Introduction
}

Mild steel is the most common steel used. Many of the objects created from steel are made of mild steel, including automobile chassis, motorcycle frames, and most cookware. Mild steel is weldable, very hard, and very durable. However, it will be rust when exposed to neutral $\mathrm{pH}$ water, saltwater or high humidity air. In order to prevent rust from damaging it, there are numerous methods and many of them involve a barrier layer between the steel and the environment. This barrier layer can be a sacrificial coating, such as zinc or aluminum, or an organic coating, such as paints, waxes or oils, or a barrier oxide [1, 2].

It is well known that magnetite $\left(\mathrm{Fe}_{3} \mathrm{O}_{4}\right)$, a ferromagnetic ore compound, is one form of ir on oxides like hematite $\left(\alpha-\mathrm{Fe}_{2} \mathrm{O}_{3}\right)$, maghemite $\left(\gamma-\mathrm{Fe}_{2} \mathrm{O}_{3}\right)$, and wustite (FeO). Magnetite is als o the oldest magnetic material known to mankind. It presents the most interesting properties 
because of the presence of iron cations in two valence states, $\mathrm{Fe}^{2+}$ and $\mathrm{Fe}^{3+}$, in the inverse spinel structure [3]. Due to its interesting magnetic properties, $\mathrm{Fe}_{3} \mathrm{O}_{4}$ has important applications in pigment, recording materials [4], photocatalys is [5], ferrofluid technology [6] and magnetic refrigeration [7]. Recently, magnetite in thin film form has been attracting extensive research interest due to its application in modern magnetic devices [8-14]. Therefore, the preparation of $\mathrm{Fe}_{3} \mathrm{O}_{4}$ thin films has attracted much attention.

In this work, the blackening method will be carried out by hydrothermal electrolys is to form a passive oxide film, usually black magnetite, on the surface of carbon steel. This oxide coating has many advantages such as a strong adhesion between substrate and film, a good lubrication and a strong corrosion resistance. Farrell [15] reported that hot alkaline nitrate black oxide was originally developed in Germany as a two-bath system during the early 1900s. Next, the modern single bath oxidizing solutions became commercially prevalent during the later 1930s. Modern hot black oxidizing solutions are proprietary blends of sodium hydroxide, sodium nitrate, sodium nitrite, wetting agents, and unique rectifiers supplied as powdered compositions or ready-to-use liquid formulations. This process consists of five steps: (1) hot alkaline soak clean to remove grease and oils, (2) overflowing cold water rinse, (3) blackening, (4) overflowing cold water rinse, (5) final seal with a water displacing oil, a wax, an acrylic, or a soluble oil. This process is simple, however, the chemical agent such as nitrate is considered to be a hazardous substance that can cause cancer for human body [16,17]. Therefore, the development of environmental-friendly blackening processes is still of considerable attractive to industries.

At hydrothermal conditions, the oxidation of iron is accomplished by the reduction of hydrogen ions supplied by the hot water [18]. The magnetite film is thus formed directly.

$$
\mathrm{Fe}+\mathrm{H}_{2} \mathrm{O} \rightarrow \mathrm{Fe}_{3} \mathrm{O}_{4}+\mathrm{H}_{2}
$$

The formation of a magnetite film, although highly desirable, is itself a form of corrosion. This 
view of the corrosion process is more complicated than above showed chemical reaction and include physico-chemical reactions which probably includes secondary reactions. Under adverse conditions, such as the $\mathrm{pH}$ is either too high or too low, the coarse magnetite film may form in the water as well as on steel surfaces. This magnetite film is less than ideal and tends not to be stable film. The use of sodium hydroxide as a solution will promote the soluble sodium hypoferrite. This reaction can remove the protective magnetite film by the following reactions:

$$
\mathrm{NaOH}+\mathrm{Fe}_{3} \mathrm{O}_{4} \rightarrow \mathrm{NaFeO}_{2}+\mathrm{Na}_{2} \mathrm{FeO}_{2}+\mathrm{H}_{2} \mathrm{O}
$$

Next, sodium hydroxide can then react with freshly exposed base metal to yield sodium ferroate and atomic hydrogen.

$$
\mathrm{Fe}+\mathrm{NaOH} \rightarrow \mathrm{Na}_{2} \mathrm{FeO}_{2}+\mathrm{H}
$$

Several literatures have reported that hydrothermal method has been becoming one of the most important wet-chemical routes for synthesizing nanostructured materials [19-26]. Hydrothermal method is based on the use of water as solvent at temperatures between 100 and $374{ }^{\circ} \mathrm{C}$ and under pressure high enough to maintain the liquid state and lead to increase the solubility of a solid and to speed up reactions between solids. Zhu et al. [20] developed a hydrothermal method for growing magnetite coating on the surface of carbon steel in $\mathrm{N}_{2} \mathrm{H}_{4} \cdot \mathrm{H}_{2} \mathrm{O}-\mathrm{FeSO} \mathrm{S}_{4}-\mathrm{NaOH}$ solution at $150{ }^{\circ} \mathrm{C}$. They have successfully prepared $\mathrm{Fe}_{3} \mathrm{O}_{4}$ thin film on the surface of steel. But this method has a weakness. This method used hydrazine hydrate as the mineralizer which is toxic for human being and cause long-term harm to the environment as documented in MSDS (material safety data sheet). Chen et al. [21] has also developed a 'green' hydrothermal process for preparing $\mathrm{Fe}_{3} \mathrm{O}_{4}$ film on bare Fe foil. They used $\mathrm{FeSO}_{4} .7 \mathrm{H}_{2} \mathrm{O}$ as the iron source and $\mathrm{H}_{2} \mathrm{O}_{2}$ as the oxidant which is harmless and environmentally friendly. They have successfully formed the octadecahedron morphology that was rare but they still didn't study about the effect of temperature and pressure to the formation of the magnetite film. Recently, Whalen et al. [22] showed a simple practical approach for the formation of acmite $\left(\mathrm{NaFeSi}_{2} \mathrm{O}_{6}\right)$ coatings with a 
uniform, passivating coverage on steel at substantially mild reaction conditions. Acmite films were formed on steel via solvothermal reaction of silica, sodium hydroxide, and 1,4-butanediol in an autoclave under autogenous pressure at $240{ }^{\circ} \mathrm{C}$. However, the long reaction time was needed (72 h) to create coverage of the steel substrate with acmite. Freire et al. [25] conducted experiments for iron oxide thin layers formation on mild steel substrates in alkaline media by the application of different anodic potentials. Surface analysis revealed the existence of a duplex structure in the passive layer: an inner layer rich in $\mathrm{Fe}^{2+}$ oxides whose thickness depends on the potential, and an outer layer richer in $\mathrm{Fe}^{3+}$ hydroxides. They concluded that the cathodic prevention can be applied to modify the structure of the passive film and make cathodic protection more efficient. Ayman et al. [26] suggested that the magnetite films assembled on the iron surface can protect the iron from corrosion efficiently. Again, the long reaction time was needed.

In order to improve the rate of the blackening process, the electrochemical process was employed [1, 2, 27-32]. Bacsa et al. [29] introduced the hydrothermal-electrochemical technique to synthesis barium titanate $\left(\mathrm{BaTiO}_{3}\right)$ at temperatures $80-200{ }^{\circ} \mathrm{C}$ with titanium as an electrode and barium hydroxide $\left(\mathrm{Ba}(\mathrm{OH})_{2}\right)$ as an electrolyte solution. They reported that the films of cubic $\mathrm{BaTiO}_{3}$ could be produced in the electrochemical process by the anodization of a titanium substrate in barium hydroxide solution. They explained that after the first layer of $\mathrm{BaTiO}_{3}$ is formed, the growth continues because of the possibility of the dissolution of $\mathrm{BaTiO}_{3}$ during the process. Then, the dissolution of $\mathrm{BaTiO}_{3}$ may expose fresh metal surface to the electrolyte and the reaction may continue through the pores formed. Kajiyoshi et al. [30] also succeed to synthesis strontium titanate $\left(\mathrm{SrTiO}_{3}\right)$ by using hydrothermal-electrochemical technique. The thin films of strontium titanate could grow on titanium electrodes up to ca. $2 \mu \mathrm{m}$ in thickness. Next, Burleigh et al. [1,2] demonstrated the possibility to electrochemically grow an adherent blue-black magnetite layer, a light brown oxide, or a semiadherent dichroic magnetite layer on 
many different types of steel in either $\mathrm{KOH}$ or $\mathrm{NaOH}$ solutions. The adherent, blue black magnetite layer that provide corrosion protection can be grown several micrometers thick on some carbon steels by selecting a narrow range of temperature, voltage and electrode spacing. Klimas et al. [28] reported the formation of anodic film on the surface of the same type of stainless steel by direct current anodizing in electrolyte that comprised glycerol and $\mathrm{NH}_{4} \mathrm{~F}$ with and without $\mathrm{H}_{2} \mathrm{O}$ at elevated temperatures. The formation of anodic films are composed of both amorphous and crystalline species whose composition and contents depend on the anodizing conditions and the content of $\mathrm{H}_{2} \mathrm{O}$ in solution. However, the long reaction time was needed to obtain the desirable products so that the energy consumption becomes high.

Here, as described above, hydrothermal electrolys is would be utilized to prepare magnetite film. In this system, water would be conditioned at temperatures ranging between 100 and $374{ }^{\circ} \mathrm{C}$ under high enough pressure to maintain water in the liquid state. At these conditions, dielectric constant, which can be changed by temperature, is the most important factor when using water as an reaction solvent; it decreases from 78 (at room temperature) to 34 (at $200{ }^{\circ} \mathrm{C}$ ). Therefore, the reaction rate, equilibrium, and solubility of metal oxides were also could be controlled [33]. The effect of experimental parameters, such as current, $\mathrm{NaOH}$ concentration, reaction time, and temperature, on the formation of oxide film are investigated. The protective behavior against corrosion on carbon steel is evaluated using cyclic voltammetry, linear polarization and electrochemical impedance spectroscopy. This method is not often performed owing to the severe reaction conditions. Some interesting reaction behavior different to the general electrochemical reaction under ambient temperature and pressure has been conf irmed for hydrothermal electrolys is [34,35]. The main advantages of this technique over the conventional hydrothermal method are improved purity of the products, lower reaction temperature and higher film growth rates [31,32]. This suggests that the method has some potential as a novel phenomenon and is different from the conventional reaction. 


\section{Material and Methods}

\subsection{Material}

Specimens of commercial mild steel, $3 \mathrm{~mm} \times 15 \mathrm{~mm}$, were used throughout the experiments. The elemental composition of the mild steel used for electrochemical measurements is given in Table 1. Distilled water obtained from a water distillation apparatus (Shibata Co., model PW-16, Japan) was used as a solvent. Sodium hydroxide (NaOH, 97.0\%), hydrochloric acid ( $\mathrm{HCl}, 35.0 \sim 37.0 \%)$, sodium acetate $\left(\mathrm{CH}_{3} \mathrm{COONa} 98.5 \%\right)$, and acetic acid $\left(\mathrm{CH}_{3} \mathrm{COOH}, 99.7\right.$ \%) were purchased from Wako Pure Chemicals Industries Ltd., Japan, and were used without further purification.

\subsection{Experimental Method}

The experiments of magnetite film formation by hydrothermal electrolys is were carried out in batch autoclave at a controlled temperature. Fig. 1 showed the hydrothermal electrolysis apparatus used in this work. The apparatus consists of a high-pressure vessel inclusive cartridge heater (Akico, Japan), pyrex beaker (500 ml in volume; Akico, Japan) and back-pressure regulators (BPR; Akico, Japan). At the beginning of the experiment, the $\mathrm{NaOH}$ solution as an electrolyte (200 mL) was loaded in pyrex beaker and placed in the autoclave. The concentrations of $\mathrm{NaOH}$ solution were $2.5-15 \%$ [g/L]. This electrolyte solution ( $\mathrm{NaOH}$ solution) was selected based on the previous research report [1,2]. Burleigh et al. [1,2] demonstrated that it is possible to anodize steel in either $\mathrm{KOH}$ or $\mathrm{NaOH}$ solutions and grow an adherent oxide on the steel surface. The mild steel to be anodized was connected to the positive terminal of the power supply (ZX-400L, Takasago Ltd., Japan) and a mild steel counter electrode was connected to the negative terminal. Then the mild steels were dipped vertically into the anodizing solution. Prior to anodizing process, the mild steel plate was cut into several square pieces ( $3 \mathrm{~mm} \times 15 \mathrm{~mm} \times 50$ 
$\mathrm{mm}$ ). The square pieces were polished using abrasive paper (No. 600), and then subsequently rinsed with $\mathrm{HCl} 15 \%$ to remove the remaining debris during polishing process, and immediately washed with de-ionized water. After its lid was closed tightly, the air in the autoclave was purged and pressurized with argon gas. This internal pressure of the autoclave was defined as the initial pressure of the experiment. The $\mathrm{NaOH}$ solution loaded in the autoclave expanded thermally as the temperature in the autoclave increased and subsequently the internal pressure gradually increased. In detail, after repeated purging (basically three times) of the gas in the autoclave using argon gas with a pressure of about $0.5 \mathrm{MPa}$, it was pressurized to $0.5 \mathrm{MPa}$ with argon gas and then heated up to the desired temperature. After the temperature reached, the pressure inside increased from 0.5 $\mathrm{MPa}$ to $1-2 \mathrm{MPa}$. A thermocouple (K-type) was connected to the temperature pocket, which had been filled with silicone oil. The same method was used for throughout the experiments. The electric current is applied in the autoclave when the whole system reached the desired condition. The reaction times were measured from the applying of the electric current on the autoclave. After the reaction time had elapsed, the electric current was cut off and the autoclave was cooled until the temperature became less than $40{ }^{\circ} \mathrm{C}$. In this experiment, the time for heating to the reaction temperature and quenching to room temperature as much as possible was shortened. All the experiments were carried out at constant heating and quenching rates. In this work, the hydrothermal electrolysis was conducted at temperatures of

100-200 ${ }^{\circ} \mathrm{C}$ with 1-4 ampere of applied currents. The effect of anodizing time was also investigated and was varied from 5 to 60 minutes. The distance between electrodes was fixed at $3 \mathrm{~cm}$. After the process, the coated steel was washed with distilled water and dried in desiccator at room temperature until next characterization.

\subsection{Magnetite Film Characterization Method}

The corrosion resistance of the coated mild steel and porosity was analyzed by cyclic 
voltammetry (CV) using HZ-3000 Automatic Polarization System apparatus. This CV test was conducted using a three-electrode system. The working, counter, and reference electrodes were the coated mild steel, a platinum plate and Ag/AgCl, respectively. A platinum electrode (Pt, Hokuto Denko, $10 \times 20 \times 0.1 \mathrm{~mm}^{3}$ ) was employed as a counter-, and a silver/silver chloride couple (Ag/AgCl, Hokuto Denko, HS205-C) was as a reference electrode. This test was conducted in $100 \mathrm{~mL}$ of acetate buffer solution with $\mathrm{pH} 5.3$ at potential range between $-1 \mathrm{~V}$ and $+2 \mathrm{~V}$ with scan rate was $100 \mathrm{mV} / \mathrm{s}$. Acetate buffer solution was prepared from $0.1 \mathrm{M}$ sodium acetate and the $\mathrm{pH}$ was adjusted with acetic acid. The coated mild steel was covered to reveal a 1 $\mathrm{cm}^{2}$ surface area contacted with the solution.

The surface morphology and thickness of the prepared magnetite film was characterized by FE-SEM analysis Hitachi SU8000 Scanning Electron Microscopy. In this characterization, the secondary electron mode was used to inspect the surface of mild steel and to visualize their grain structure and gra in boundaries. The thermal electrons accelerated by voltage of about 2-15 $\mathrm{kV}$ were bombarded on the mild steel specimen, and the secondary electron ejected from the sample were detected in vacuum chamber. Gold coating to the samples was carried out before observations. X-ray diffraction (XRD) patterns were determined to confirm that magnetite was formed in the surface of mild steel. A Rigaku RINT 2100/PC XRD machine (40 kV and $200 \mathrm{~mA}$ ) equipped with a $\theta-\theta$ wide-angle goniometer and scintillation detector was used for all XRD measurements, using $\mathrm{Cu} \mathrm{K \alpha}$ radiation $(\lambda=1.5406 \AA)$.

\section{Results and Discussion}

\subsection{Characte rization of products on mild steel surfaces}

Fig. 2 describes the XRD patterns of the bare mild steel and magnetite film coated mild steel. As shown in Fig. 2(a), the most prominent peaks are observed at $2 \theta=44.54^{\circ}, 64.99^{\circ}$, $82.35^{\circ}$, and $98.96^{\circ}$ which assigned to the existence of iron in bare mild steel. For magnetite 
identification the JCPDS system was used, after estimating the distance between the planes and the intensity relative to each phase. Fig. 2(b) and 2(c) showed that the peaks with multiple orientations occurred on the surface of mild steel after treatment by hydrothermal and hydrothermal electrolys is. The XRD pattern of treated mild steel samples exhibited quite different from that of the bare mild steel sample. It was well known that steel corrosion can largely be attributed to the oxidation of iron at the material's surface. Consequently, there is possibility for the formation of iron oxides such as wustite, hematite, maghemite, and magnetite and various forms of iron hydroxide on the mild steel surface at hydrothermal conditions. Based on the simple match well with the standard XRD data for bulk magnetite (JCPDS file No. 19-0629), the position and relative intensity of the diffraction all peaks can be indexed to cubic spinel magnetite, except for those of the mild steel substrate. Therefore, it can be concluded that the black coating on the mild steel surface was $\mathrm{Fe}_{3} \mathrm{O}_{4}$. Farrell [15] reported that the magnetite film could be formed directly by immersing the steel parts in the alkaline solution under hydrothermal conditions. The layers of magnetite film on steel surface were formed via oxidation-reduction reactions in chemical solution. Rihan and Nesic [36] expla ined that under hydrothermal alkaline solutions, the most often related to formation of a protective film on the mild steel surface is magnetite film, although there are a few proposals suggesting different mechanisms for this process. Whalen et al. [22] also reported conversion of steel surfaces to magnetite in highly alkaline oxidizing baths containing $\mathrm{NaOH}$ at $240{ }^{\circ} \mathrm{C}$ with autogenous pressure. They explained that the initial surface of steel was converted into magnetite and then after additional reaction time (72 h), only acmite was apparent at the surface of steel.

Generally, low-cost precursors such as nitrate or acetate salts, hydroxides are used and dissolved in water when the hydrothermal synthesis process was utilized. The precursor solution was introduced into an autoc lave operated under hydrothermal conditions. This method has a feasibility to adjust the direction of crystal growth, morphology, particle size and size 
distribution, because of the controllability of thermodynamics and transport properties by pressure and temperature. As shown in Fig. 2(b), magnetite film has been produced on the surface of mild steel after treatment by hydrothermal at $200{ }^{\circ} \mathrm{C}$ with $6 \mathrm{~h}$ reaction time. At this condition, iron as a main component of mild steel interacts with salt was then hydrolized to iron hydroxide. Next, the iron oxide film was generated and precipitated on the surface of mild steel. High concentration of the ion product promotes hydrolysis reaction and enhances production of iron oxide film. However, the reaction time was still long. On the contrary, magnetite film was found dominantly (Fig. 2(c)) on the surface of mild steel after treatment by hydrothermal electrolys is with 60 min reaction at the same reaction temperature. The principle of hydrothermal electrolys is is applying current directly to water at hydrothermal conditions. Here, $\mathrm{NaOH}$ solution was loaded into autoclave to substitute of pure water. As explained before, the iron is hydrolized and deposited on the mild steel surface at hydrothermal condition. When electric current is passed through a $\mathrm{NaOH}$ solution, the iron would be deposited on the mild steel surface which placed as a cathode. Judging from the results, it could be said that applying current under hydrothermal condition clearly improves the formation of magnetite films on the surface of mild steel with shorter reaction time. Kothari et al [37] demonstrated that magnetite films can be deposited by the electrochemical reduction of a Fe(III)-triethanolamine complex in aqueous alkaline solution. They reported that the films were deposited with a columnar microstructure and a [100] preferred orientation on stainless steel substrates. Meng et al. [38] also conducted electrodeposition to fabricate magnetite coated carbon fibers with the same solution which was used by Kothari and co-workers. They confirmed that uniform and compact magnetite films were fabricated and deposited on the surface of carbon fibers at 2 min reaction time.

\subsection{Hydrothermal electrolysis}

Fig. 3 showed the XRD patterns of mild steel after treatment by hydrothermal 
electrolys is at various reaction temperatures with 1 ampere current applied and 60 min reaction time. Although the XRD patterns in Fig. 2 and 3 are almost similar, the intensity of diffraction line which ascribed to the formation of magnetite films can be distinguished. The results showed clearly that the increasing temperature might improve the growth rate of the magnetite film on mild steel surface at these range temperatures. Yoshimura et al. [39] reported that one of the advantages metal oxide films formation in hydrothermal-electrochemical techniques are relatively high growth rate of the films. They also explained other advantages by this system are: (1) one step (direct) formation of shaped/sized/deposited/oriented ceramics; (2) low consumption of energy; (3) any shape, any size; (4) possibility of using a closed flow system, allowing easy charging, separation, cycling and recycling; (5) versatility. In addition, this hydrothermal-electrochemical technique also gave products with much higher homogeneity than solid state processing. Huang et al. [40] suggested that the increasing alkaline solution temperature $\left(<300{ }^{\circ} \mathrm{C}\right)$, the mass transportation rate of the solution greatly increased resulting the thickness of the passive films increases. Therefore, it could be said that the reaction temperature of hydrothermal treatment is the key variable parameter to get magnetite film on the surface of mild steel [2].

Fig. 4 showed the photographs of mild steel after anodizing by hydrothermal electrolysis at various conditions such as reaction temperatures, reaction times, $\mathrm{NaOH}$ concentration, and current density. These figures described that the dense black coating on the mild steel surface almost grew clearly. These results are similar to the previous results reported by Burleigh et al. $[1,2]$. They explained that the magnetite film on the steel surface has many different optical appearances, including black, dichroic, and a light brown color, depending on the operating conditions such as temperature and applied potential. The term dichroic refers to a surface that reflects different colors when viewed at different angles. As can be seen from this figure, the differences of color on the mild steel surface were found significantly when the reactions were 
conducted at various temperatures. At $100{ }^{\circ} \mathrm{C}$, brown color appeared on the mild steel surface which had metallic blue as a dominant color. When the reaction temperatures were increased at the same parameters (reaction times, $\mathrm{NaOH}$ concentration, and current density), the mild steel surface color become black clearly. As explained before, during the anodization process by hydrothermal electrolys is, the increasing reaction temperature could enhance the growth rate of the oxide films on mild steel surface. Again, this result conf irmed that the increasing temperature of electrolyte in this electrolys is system increased the growth rate of the oxide films. These figures also showed that reaction times, electrolyte concentrations, and current densities had influence on the anodizing process. In general, the expansion of these parameters would be followed by the growth rate of the oxide films. Burleigh et al. [2] reported that the increasing concentration of the $\mathrm{NaOH}$ or $\mathrm{KOH}$ as an electrolyte could increase the anodic oxide growth rate in nanometers per second on the steel surface. Huang et al. [41] concluded that higher electrolyte concentration results in faster growth rate of anodic aluminum oxide films while it has little influence on the pore size and inter pore distance. High electrolyte concentration could also promote the branched growth of anodic aluminum oxide during a voltage lowering process, which opens new avenue for the fabrication of new types of nanostructured channels. In addition, Burleigh et al. [2] and Huang et al. [41] also informed that there was a limit for the applied voltage during anodizing process. When anodizing voltage exceeds the upper limit value, burning often happens due to large heat generated at high current density. Less of the current went into oxide growth and more of the current went into iron dissolution and oxygen evolution. In the present experiments, magnetite film formed in $5 \% \mathrm{NaOH}$ with $0.2 \mathrm{~A} / \mathrm{cm}^{2}$ current density seems to be optimum condition when the reaction temperature was $200{ }^{\circ} \mathrm{C}$ with 5 min reaction time. Finally, it could be said that the different color on the surface of mild steel might be caused by the different thicknesses of magnetite films on mild steel surface. 


\subsection{Morphology and thickness}

Generally, the thickness of oxide films could be grown on the metals or alloys surface by thermal oxidation in air at a specific temperature, chemical oxidation or electrochemical oxidation. Anodizing is extensively known as the electrochemical method of providing an artificially thickened oxide films on the surface of metals or alloys. Due to the redox reactions involved in the chemical oxidation process did not occur at room temperature spontaneously, various electrochemical oxidation methods with strong oxidizing solutions under reducing environment have been proposed to produce oxide films. As shown before, magnetite films with several colors (see Fig. 4) were successfully generated on the surface of mild steel, depending on parameters such as reaction temperatures, reaction times, electrolyte concentrations, and applied current density. Fig. 5 showed the thickness of magnetite films produced under various experimental conditions. The thickness of the magnetite films was measured from FE-SEM images in cross section. The difference morphology between films formed and mild steel substrate were obtained clearly. From these figures it could be known that the increasing temperature up to $200{ }^{\circ} \mathrm{C}$ did not change significantly to the thickness of films on mild steel surface $[2,42,43]$. At $200{ }^{\circ} \mathrm{C}$, the thickness of films was about $126.72 \mu \mathrm{m}$. Song et al. [43] have clearly shown the usefulness of the hydrothermal process for the direct fabrication of films on a cobalt substrate at $20-200{ }^{\circ} \mathrm{C}$. They explained that increasing the fabrication temperature promotes the nucleation and crystal growth rate of the film and causes an increased film thickness, reaching $\sim 18 \mu \mathrm{m}$ at $125^{\circ} \mathrm{C}$, that remains almost constant at $>125^{\circ} \mathrm{C}$, but the grain size of the film continuously increases from 0.2 to $1.1 \mu \mathrm{m}$. Burleigh et al. [2] also suggested that increasing the reaction temperature resulted in a thicker oxide after 5 min reaction time, but only up to a limit. With increasing reaction temperature the aggressiveness of the electrolyte towards the oxide increases accordingly, hence enhancing the chemical dissolution of the magnetite films by the electrolyte. They [2,43] concluded that the formation of films under their hydrothermal 
conditions might be based on the dissolution-precipitation mechanism. Based on the results, it could be said that reaction temperature as one of the anodizing parameters process did not highly influence on the magnetite film formation under hydrothermal electrolys is at these range temperatures. As reported by Burleigh et al. [2], with an increase in reaction time, electrolytes concentration, and current density, the thickness of films also increase to reach a steady state thickness. After that, the oxide films do not grow. Huang et al. [41] found that the high electrolyte concentration can promote the growth rate without affecting the pore size and inter pore distance of anodic aluminum oxide. However, they remind that although higher growth rate of anodic aluminum oxide can be obtained in more concentrated electrolyte, anodization should be carefully performed to avoid burning. As shown in the Fig. 5, the present study showed that increasing concentration of electrolyte also resulted in thicker magnetite film due to the faster reaction rate. These figures also showed the magnetite films thickness as a function of anodization time for $0.1 \mathrm{~A} / \mathrm{cm}^{2}$ applied current density in $5 \% \mathrm{NaOH}$ concentration under $200{ }^{\circ} \mathrm{C}$ reaction time. It showed that magnetite films thickness increased with increase in anodization time. At $5 \mathrm{~min}$, the thickness of magnetite film was $25.62 \mu \mathrm{m}$ then increased to $126.72 \mu \mathrm{m}$ at 60 min reaction time. Judging from the results, it could be said that the thickness of magnetite films is proportionally increased with increasing reaction time. In general, the effect of the current density on the electrochemical oxide growth behaviors is not only qualitatively in opposition to the effect of the electrolyte concentration but also quantitatively much greater; an increase of the current density increases the anodic forming voltage while an increase of the electrolyte concentration decreases it [44]. As shown in Fig. 5, it was found obviously that the current densities effect on the magnetite film thickness. It is also shown that the thickness of magnetite films became more porous due to the increasing ions transfer and rapid solidification of iron oxide on the surface of mild steel. Therefore, the higher current density resulted in the thicker magnetite film, but only up to limit [2,41]. 


\subsection{Cyclic voltammetry of mild steel coated}

In order to study the corrosion resistance of the coatings, the electrochemical properties of mild steel coated by magnetite film was characterized with cyclic voltammetry in acetate buffer as an aqueous electrolyte solution. This analys is is a very common potentiodynamic electrochemical measurement technique, which is widely used to investigate and describe electrochemical properties of an electrical conductive system. The procedure became popular because it allows forming thicker films and simultaneously acquiring qualitative information on the electrochemical reactions. In particular, it offers a rapid identification of the redox potentials of the electroactive species, and an accurate evaluation of the effect of the media on the redox processes [45]. Fig. 6 showed the cyclic voltammograms after 10 cycles for mild steel before and after treatment by hydrothermal $\left(200{ }^{\circ} \mathrm{C} ; 6 \mathrm{~h}\right)$ and hydrothermal electrolys is $\left(200{ }^{\circ} \mathrm{C}\right.$; $60 \mathrm{~min} ; 0.2$ $\mathrm{mA} / \mathrm{cm}^{2}$ ). The cyclic voltammetry curves did not change even after more than 10 cycles. It indicated that the analysis condition allows relaxation of the redox processes that take place in the passive layer and defining the reactions taking place in the electrode surface [45]. At the beginning of scan, the anodic current increases as the potential rises, and reaches a maximum value of current where the reaction was started. The more positive potentials, the current decreased and the steel sample was passivated. The raising of the cyclic voltammogram involves peak is probably due to the active substrate dissolution to form ferrous hydroxide [46]. Deyab and Keera [46] explained that when the concentration of ferrous oxide at the anodic surface exceeds its solubility product, precipitation of solid oxide occurred on the electrode surface. When the surface is entirely covered with oxide passive film, the anodic current density falls to a low value, and it is indicating the onset of passivation. As shown in Fig. 6, it could be seen that the mild steel after treatment by hydrothermal or hydrothermal electrolysis had lower Imax 
films have been generated on the surface of mild steel. The initial current of mild steel after hydrothermal treatment is not significantly higher than hydrothermal electrolys is mild steel treated but the peaks do have different shapes, particularly the anodic peaks. In other words, the anodic current densities of mild steel electrode treated by hydrothermal and hydrothermal electrolys is fall to lower values compared to a bare mild steel electrode. It indicated that a protective film iron oxide (magnetite film) was generated on the surface of mild steel treated by hydrothermal and hydrothermal electrolysis. Table 2 showed the Imax value of hydrothermal electrolys is mild steel treated at various conditions. It could be seen that the corrosion resistance of the mild steel almost increased with increasing anodizing temperature and reaction time. The results also confirmed that the color and the thickness of magnetite films on the mild steel surface were darker and thicker with increasing anodizing temperature and reaction time.

\subsection{Hydrothermal electrolysis}

As explained before, hydrothermal method is a simple and powerful method for obtaining films ranging from hundreds of nanometers to a few micrometers grown on metal substrates. In this method, the growth solution was loaded in autoclaves, and temperature is increased above boiling point and below critical point of water by increasing autogenous pressure from heating. Because of elevated temperature and pressure in the autoclaves, solubility of chemical compounds increased compared to ambient environment. Generally, the synthesis of a metal oxide under hydrothermal conditions can be visualized as follows [32]. At the beginning of the process as the temperature is increased, the hydrolysis of a metal salt precursor produces metal hydroxides. Then, when the system has reached a more elevated temperature the hydroxides are dehydrated, yielding the metal oxide. This is favored by the decrease of the dielectric constant of water and the increase of the oxygen solubility in water due to the critical conditions. However, the desirable products might be obtained after longer periods of time. In 
order to reduce reaction time and energy savings, the electric currents was applied. A detailed mechanism has not been elucidated because, in principle, every c ompound could be obtained via different reaction pathways. In cathode, the concentration of hydrogen ions is low in highly alkaline deoxygenated solutions so the cathodic current comes primarily from direct reduction of water (dragging away of the $\mathrm{OH}^{-}$portion of the adsorbed water molecules) [36]:

$\begin{aligned} \mathrm{H}_{2} \mathrm{O}+\mathrm{e}^{-} & \rightarrow \mathrm{H}_{2}+\mathrm{OH}^{-} \\ \text {and, } \mathrm{Fe}+\mathrm{OH}^{-} & \rightarrow \mathrm{Fe}(\mathrm{OH})_{2}+\mathrm{e}^{-}\end{aligned}$

This reaction (5) dominates in anode when the reaction occurred under hydrothermal alkaline conditions. Due to the concentration of iron species was sufficiently high, the solubility product of magnetite will be exceeded, leading to deposition of a surface film. The reaction can be described as (Schikorr's reaction):

$$
\mathrm{Fe}(\mathrm{OH})_{2} \quad \rightarrow \quad \mathrm{Fe}_{3} \mathrm{O}_{4}+\mathrm{H}_{2}+\mathrm{H}_{2} \mathrm{O}
$$

This reaction is quite possible that the growth of the magnetite film proceeds according to several mechanis ms simultaneously [36]. In detail Rihan and Nesic explained that the film grows from the inner side (metal interface) via the direct oxidation mechanism, while it grows from the outside side (solution interface) side via the precipitation mechanism. In these films, due to the conf ined space, the inner layer cons ists of a small-grain, low-poros ity crystal structure, while the outer layer consists of larger, free-growing crystallites with higher porosity. As shown in Fig. 7, the surface of treated mild steel contained grain of crystallites. The amount of crystallites grain increased with an increase in temperature process. Judging the results, it could be said that the hydrothermal electrolysis is promising method to prepare magnetite thin films on mild steel surfaces. This process could improve the performance of hydrothermal process including the reduction of reactions times and energy savings. 


\section{Conclusions}

The formation of magnetite film on the surface of mild steel was studied at temperatures of $100-200{ }^{\circ} \mathrm{C}$ and applied current densities of $0.1-0.4 \mathrm{~A} / \mathrm{cm}^{2}$ with 5-60 min reaction time in sodium hydroxide $(\mathrm{NaOH})$ as an electrolyte solution. Magnetite film was characterized by X-ray diffraction (XRD), field emission scanning electron microscopy (FE-SEM), and cyclic voltammetry. The patterns of XRD showed that magnetite was formed dominantly on the surface of mild steel with black color. In the present experiments, magnetite film formed $(181.56 \mu \mathrm{m})$ in $5 \% \mathrm{NaOH}$ with $0.2 \mathrm{~A} / \mathrm{cm}^{2}$ current density seemed to be the optimum condition when the reaction temperature was $200{ }^{\circ} \mathrm{C}$ with 5 min reaction time. Cyclic voltammetry analys is showed that the magnetite films formed on the mild steel surface could prevent or minimize the corrosion on its surface. On the basis of the results, it is proposed that hydrothermal electrolysis might improve the magnetite film formation to advance coating mild steel routes and therefore this technique became the most promising technology which could be applied for other types of material. 


\section{Acknowledgements}

This work was supported by the Kumamoto University Global COE Program “Global Initiative Center for Pulsed Power Engineering” and in collaboration with Department of Chemical Engineering, Sepuluh Nopember Institute of Technology (ITS). 


\section{References}

[1] T.D. Burleigh, T.C. Dotson, K.T. Dotson, S.J. Gabay, T.B. Sloan, S.G Ferrell, J. Electrochem. Soc. 154 (2007) C579-C586.

[2] T.D. Burleigh, P. Schmuki, S. Virtanen, J. Electrochem. Soc. 156 (2009) C45-C53.

[3] T.J. Daou, G Pourroy, S. Begin-Colin, J.M. Greneche, C. Ulhaq-Bouillet, P. Legare, P. Bernhardt, C. Leuvrey, G Rogez, Chem. Mater. 18 (2006) 4399-4404.

[4] G Bate, Recording materials, in: E.P. Wohlfarth (1980.) Handbook of Magnetic Materials, Vol. 2, North-Holland Publishing Co., Amsterdam.

[5] D. Beydoun, R. Amal, GK.-C. Low, S. McEvoy, J. Phys. Chem. B 104 (2000) 4387-4396.

[6] S. Odenbach (2002) Ferrofluids Magnetically Controllable Fluids and Their Applications, Springer-Verlag, Berlin Heidelberg.

[7] R.D. McMichael, R.D. Shull, L.J. Swartzendruber, L.H. Bennett, R.E. Watson, J. Magn. Magn. Mater. 111 (1992) 29-33.

[8] S.F. Hasany, N.H. Abdurahman, A.R. Sunarti, R. Jose, Current Nanoscience 9 (2013) 561-575.

[9] G Muscas, G Concas, C Cannas, A. Musinu, A. Ardu, F. Orru, D. Fiorani, S. Laureti, D. Rinaldi, G Piccaluga, D. Peddis, J. Phys. Chem. C 117 (2013) 23378-23384.

[10] J. Sun, Z. Wang, Y. Wang, C. Yao, K. Wei, F. Li, Nucl. Instrum. Methods Phys. Res. Sec. B 269 (2011) 873-875.

[11] J. Sun, Z. Wang, Y. Wang, Y. Zhu, T. Shen, L. Pang, K. Wei, F. Li, Mater. Sci. Eng. B 177 (2012) 269-273.

[12] I. Bilecka, M. Kubli, E. Amstad, M. Niederberger, J. Sol-Gel Sci. Technol. 57 (2011) 313-322.

[13] O. Pascu, E. Carenza, M. Gich, S. Estrade, F. Peiro, G. Herranz, A. Roig, J. Phys. Chem. C 116 (2012) 15108-15116. 
[14] P.J. Thomas, Annu. Rep. Prog. Chem., Sect. A: Inorg. Chem. 109 (2013) 453-467.

[15] R.W. Farrel, Metal Finishing 1 (2002) 456-462.

[16] P. Santamaria, J. Sci. Food Agric. 86 (2006) 10-17.

[17] D.S. Powlson, T.M. Addisc ott, N. Benjamin, K.G Cassman, T.M. de Kok, H. van Grinsven, J.-L. L'hirondel, A.A. Avery, C.V. Kessel, J. Environ. Qual. 37 (2008) 291-295.

[18] C. Frayne (2002) Boiler Water Treatment Principles and Practice, Chemical Publishing Co. Inc., New York.

[19] S.V.N.T. Kuchibhatla, A.S. Karakoti, D. Bera, S. Seal, Prog. Mater. Sci. 52 (2007) 699-913.

[20] H. Zhu, F. Cao, D. Zuo, L. Zhu, D. Jin, K. Yao, Appl. Surf. Sci. 254 (2008) 5905-5909.

[21] J. Chen, K. Huang, S. Liu, J. Alloy. Compd. 484 (2009) 207-210.

[22] T. Whalen, B. VanSaders, C. Vakifahmetoglu, A. Mughal, E. Zlotnikov, S.-B. Cho, R.E. Riman, J. Am. Ceram. Soc. 96 (2013) 3656-3661.

[23] M. Yamashita, H. Nagano, T. Misawa, H.E. Townsend, ISIJ Int. 38 (1998) 285-290.

[24] R.W. Revie, H.H. Uhlig (2008) Corrosion and Corrosion Control. An Introduction to Corrosion Science and Engineering. Fourth Edition, John Wiley \& Sons, Inc., Hoboken New Jersey.

[25] L. Freire, X.R. Nóvoa, M.F. Montemor, M.J. Carmezim, Mater. Chem. Phys. 114 (2009) 962-972.

[26] A.M. Atta, O.E. El-Azabawy, H.S. Ismail, M.A. Hegazy, Corros. Sci. 53 (2011) $1680-1689$.

[27] Y. Konno, S. Yang, E. Tuji, Y. Aoki, P. Skeldon, GE. Thompson, H. Habazaki, ECS Trans. 50 (2013) 183-190.

[28] V. Klimas, V. Pakstas, I. Vrublevsky, K. Chernyakova, A. Jagminas, J. Phys. Chem. C, 117 (2013) 20730-20737. 
[29] R. Bacsa, P. Ravindranathan, J.P. Dougherty, J. Mater. Res. 7 (1992) 423-428.

[30] K. Kajiyoshi, K. Tomono, Y. Hamaji, T. Kasanami, M. Yoshimura, J. Am. Ceram. Soc. 77 (1994) 2889-2897.

[31] M. Yoshimura, K. Byrappa, J. Mater. Sci. 43 (2007) 2085-2103.

[32] J.O. Landeros, C.G Yanez, R.L. Juarez, I.D. Velasco, H. Pfeiffer, J. Adv. Ceram. 1 (2012) 204-220.

[33] T. Adschiri, Y.W. Lee, M. Goto, S. Takami, Green Chem. 13 (2011) 1380-1390.

[34] M. Sasaki, Wahyudiono, A. Yuksel, M. Goto, Fuel Process. Technol. 91 (2010) 1125-1132.

[35] A. Yuksel, M. Sasaki, M. Goto, J. Hazard. Mater. 190 (2011) 1058-1062.

[36] R.O. Rihan, S. Nesic, Corros. Sci. 48 (2006) 2633-2659.

[37] H.M. Kothari, E.A. Kulp, S.J. Limmer, P. Poizot, E.W. Bohannan, Jay A. Switzer, J. Mater. Res. 21 (2006) 293-301.

[38] X. Meng, Y. Wan, Q. Li, J. Wang, H. Luo, Appl. Surf. Sci. 257 (2011) 10808- 10814.

[39] M. Yoshimura, W. Suchanek, K.-S. Han, J. Mater. Chem. 9 (1999) 77-82.

[40] J. Huang, X. Wu, E.-H. Han, Corros. Sci. 52 (2010) 3444-3452.

[41] B. Huang, Y. Guo, Y. Tian, Y. Wen, B. Shan, R. Chen, ECS Trans. 50 (2013) 279-286.

[42] T. Aerts, Th. Dimogerontakis, I. De Graeve, J. Fransaer, H. Terryn, Surf. Coat. Technol. 201 (2007) 7310-7317.

[43] S.-W. Song, K.-S. Han, M. Yoshimura, J. Am. Ceram. Soc., 83 (2000) 2839-2844.

[44] Y.-T. Sul, C.B. Johansson, Y. Jeong, T. Albrektsson, Med. Eng. Phys. 23 (2001) 329-346.

[45] L. Freire, M.A. Catarino, M.I. Godinho, M.J. Ferreira, M.GS. Ferreira, A.M.P. Simões, M.F. Montemor, Cem. Conc. Composit. 34 (2012) 1075-1081.

[46] M.A. Deyab, S.T. Keera, Egypt J. Petrol. 21 (2012) 31-36. 


\section{Table Captions}

Table 1. Chemical composition of the mild steel.

Table 2. Preparation parameters vs Imax of mild steel treated. 


\section{Figure Captions}

Fig. 1. Experimental apparatus scheme of hydrothermal or hydrothermal electrolysis system.

Fig. 2. XRD pattern of bare mild steel before and after treatment by hydrothermal and hydrothermal electrolysis.

Fig. 3. XRD pattern of mild steel after treatment by hydrothermal electrolysis at different temperatures.

Fig. 4. Photographs of mild steel surface after anodizing by hydrothermal electrolysis at various conditions.

Fig. 5. Magnetite films thickness vs preparation parameters.

Fig. 6. Cyclic voltammograms obtained for mild steel before and after treatment by hydrothermal or hydrothermal electrolysis.

Fig. 7. SEM images of mild steel surface after anodizing by hydrothermal electrolysis at (a). $160{ }^{\circ} \mathrm{C}$ and (b). $200{ }^{\circ} \mathrm{C}$, respectively. 
Table 1. Chemical composition of the mild steel.

\begin{tabular}{lcccccc}
\hline & \multicolumn{6}{c}{ Chemical composition } \\
\hline Element \% & $\mathrm{C}$ & $\mathrm{S}$ & $\mathrm{P}$ & $\mathrm{Si}$ & $\mathrm{Mn}$ & $\mathrm{Fe}$ \\
& (Carbon) & (Sulphur) & (Phosphor) & (Silicon) & (Mangan) & (Iron) \\
Composition (w/w) & 0.027 & 0.006 & 0.008 & 0.081 & 0.340 & 99.296 \\
\hline
\end{tabular}


Table 2. Preparation parameters vs Imax of mild steel treated.

\begin{tabular}{lcc}
\hline \multicolumn{1}{c}{ Parameters } & Imax (mA) \\
\hline Temperature $\left({ }^{\circ} \mathrm{C}\right)(5 \%$ & 100 & 8 \\
$\left.\mathrm{NaOH}, 0.1 \mathrm{~A} / \mathrm{cm}^{2}, 1 \mathrm{~h}\right)$ & 120 & 3.2 \\
& 160 & 2.2 \\
& 200 & 1.8 \\
Time (min) $\left(200{ }^{\circ} \mathrm{C}, 5 \%\right.$ & 5 & 9.8 \\
$\left.\mathrm{NaOH}, 0.1 \mathrm{~A} / \mathrm{cm}^{2}\right)$ & 15 & 2.5 \\
& 30 & 7.3 \\
$\mathrm{NaOH}$ concentration $(\%)$ & 60 & 2.2 \\
$\left(200{ }^{\circ} \mathrm{C}, 5 \mathrm{~min}, 0.1 \mathrm{~A} / \mathrm{cm}^{2}\right)$ & 10 & 9.8 \\
& 15 & 3.8 \\
& 0.1 & 2.2 \\
Current density $\left(\mathrm{A} / \mathrm{cm}^{2}\right)$ & 0.2 & 4.8 \\
$\left(200{ }^{\circ} \mathrm{C}, 5\right.$ min, $\left.5 \% \mathrm{NaOH}\right)$ & 0.3 & 2.33 \\
& 0.4 & 3 \\
\hline
\end{tabular}


Fig. 1. Experimental apparatus scheme of hydrothermal or hydrothermal electrolysis system.

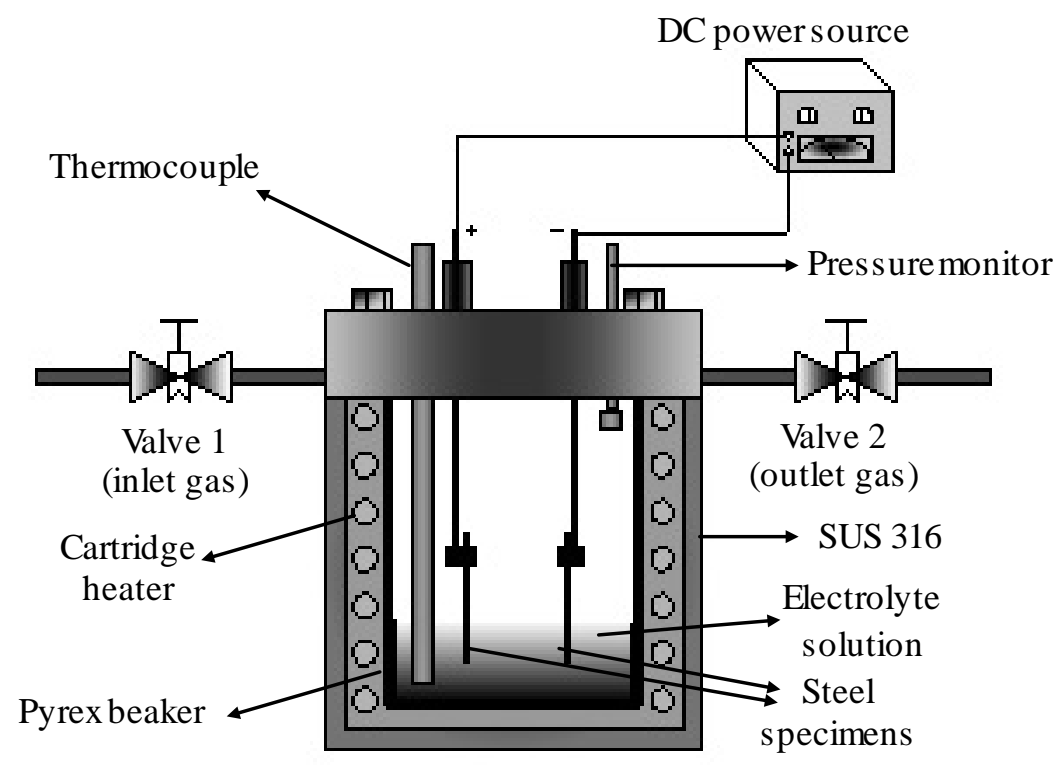


Fig. 2. XRD pattern of bare mild steel before and after treatment by hydrothermal and hydrothermal electrolysis.
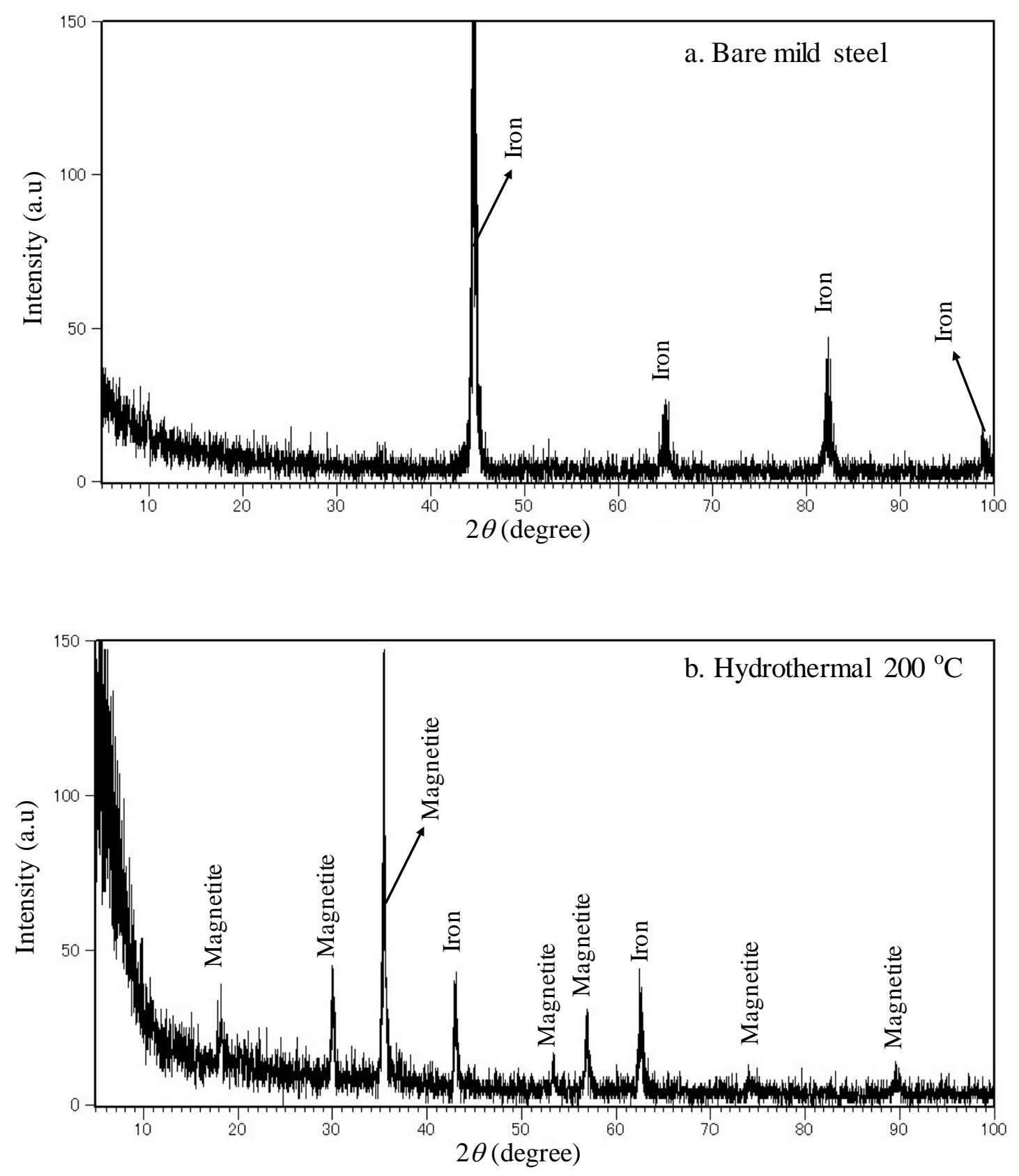


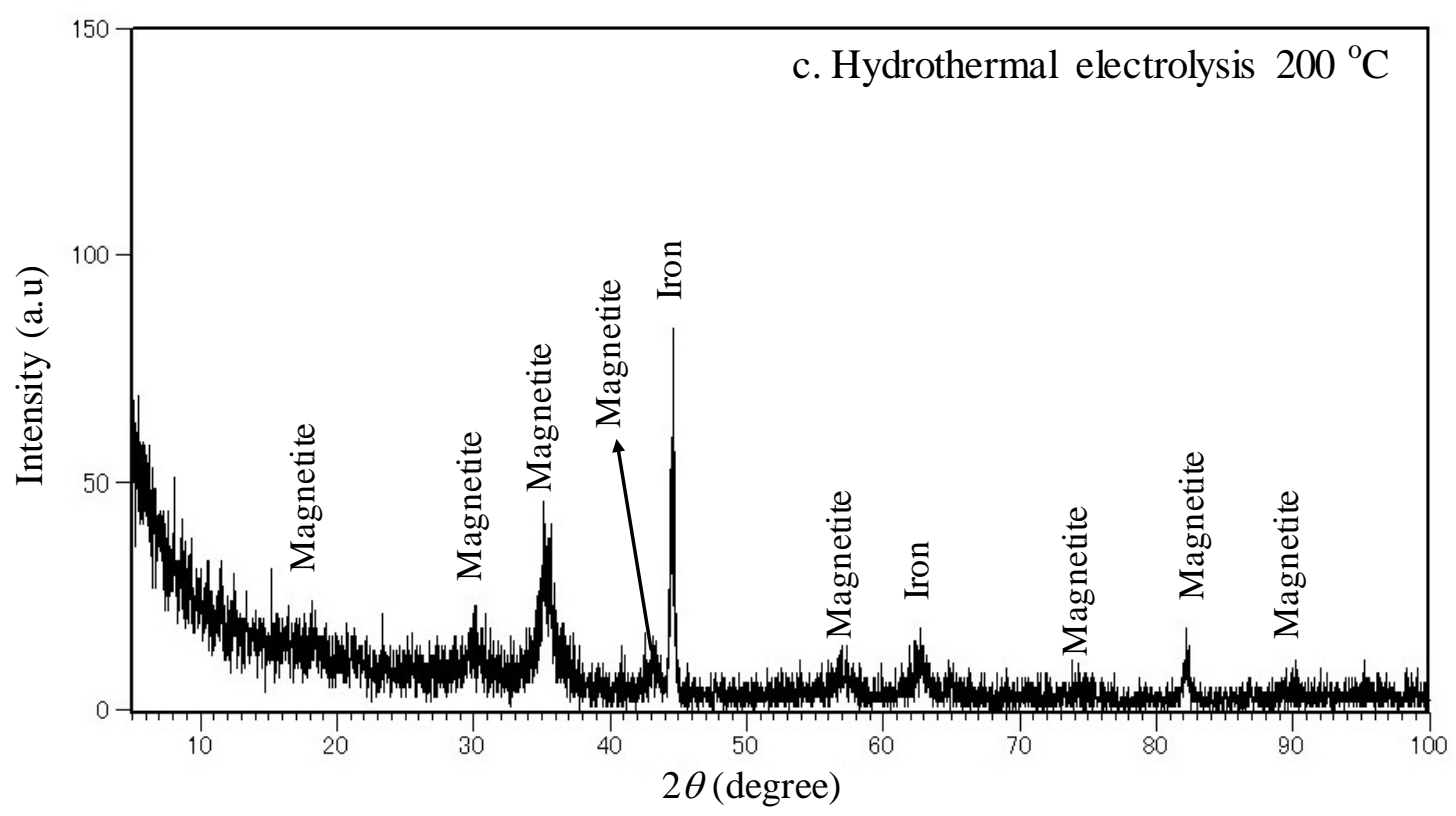


Fig. 3. XRD pattern of mild steel after treatment by hydrothermal electrolysis at different temperatures.
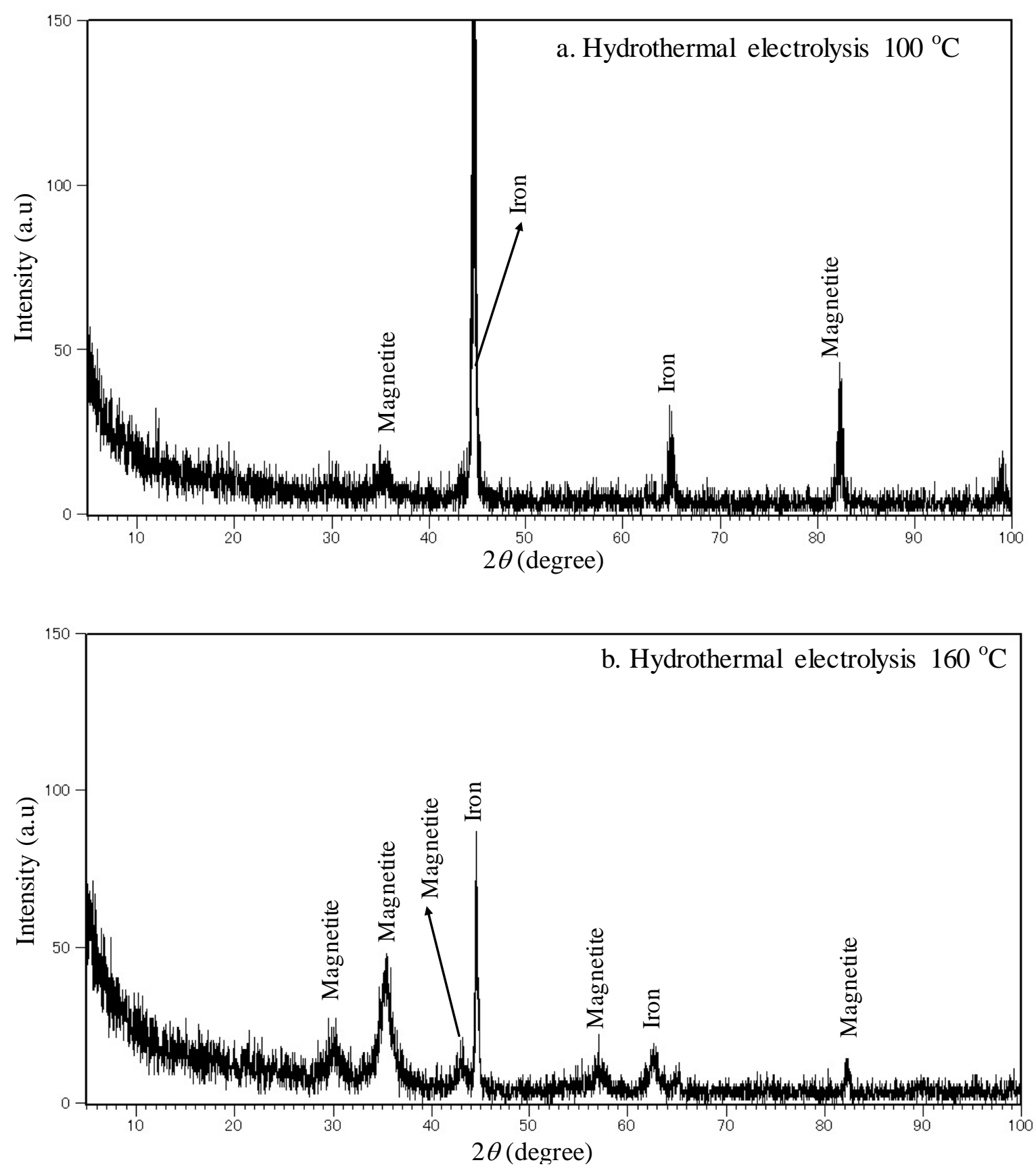
Fig. 4. Photographs of mild steel surface after anodizing by hydrothermal electrolysis at various conditions.

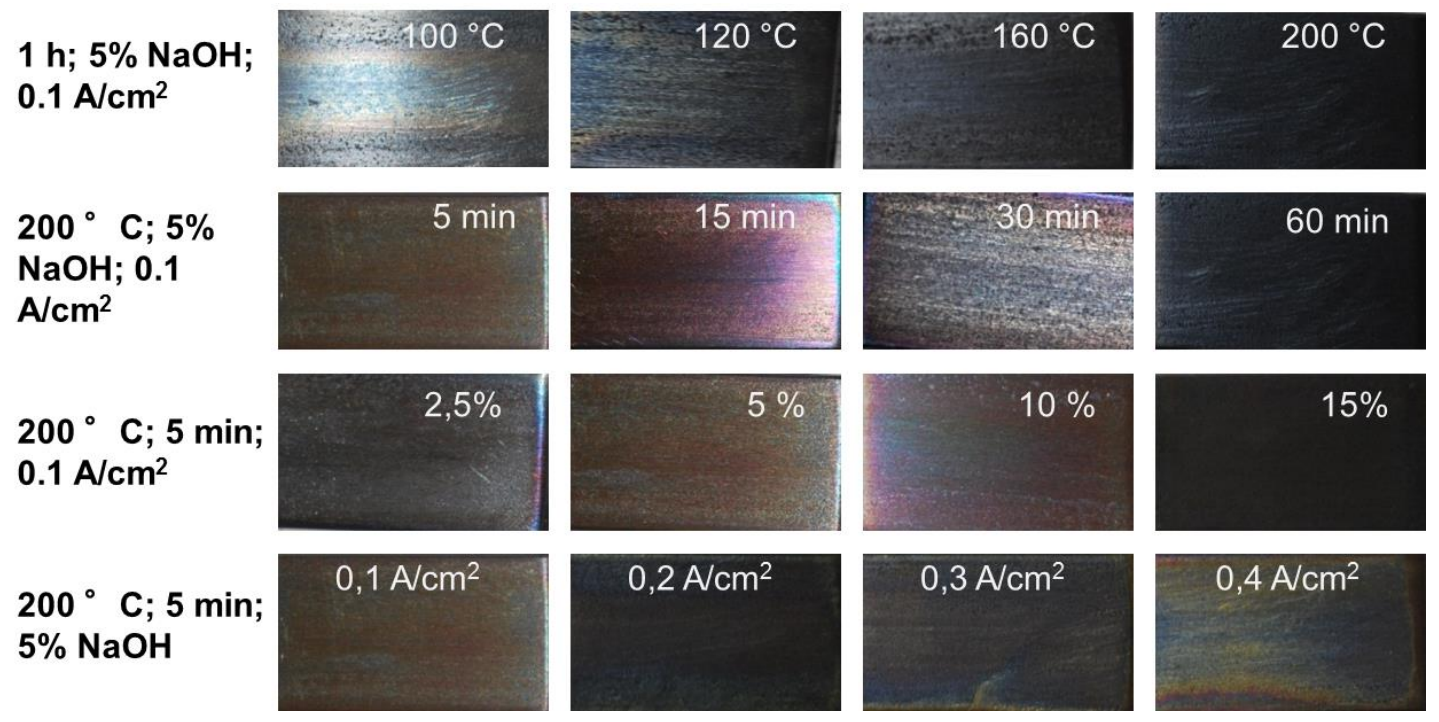


Fig. 5. Magnetite films thickness vs preparation parameters.

(a). $1 \mathrm{~h} ; 5 \% \mathrm{NaOH} ; 0.1 \mathrm{~A} / \mathrm{cm}^{2}$
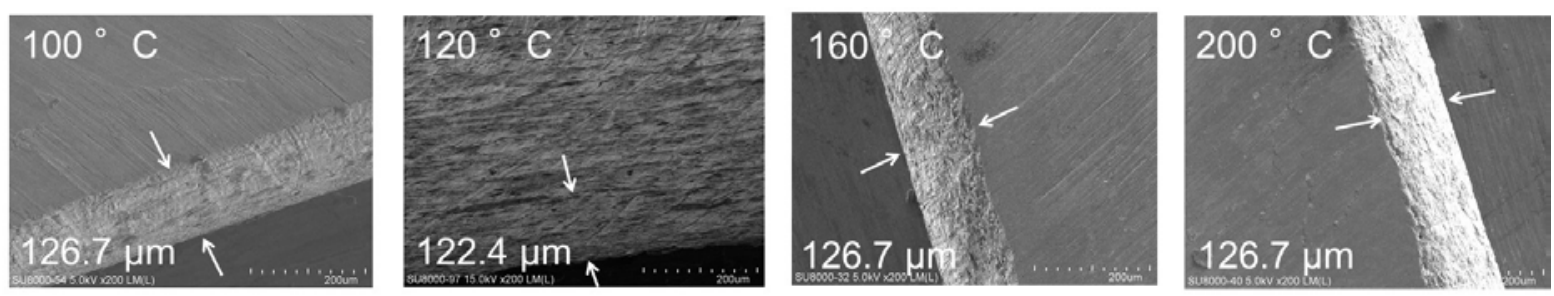

(b). $200{ }^{\circ} \mathrm{C} ; 5 \% \mathrm{NaOH} ; 0.1 \mathrm{~A} / \mathrm{cm}^{2}$
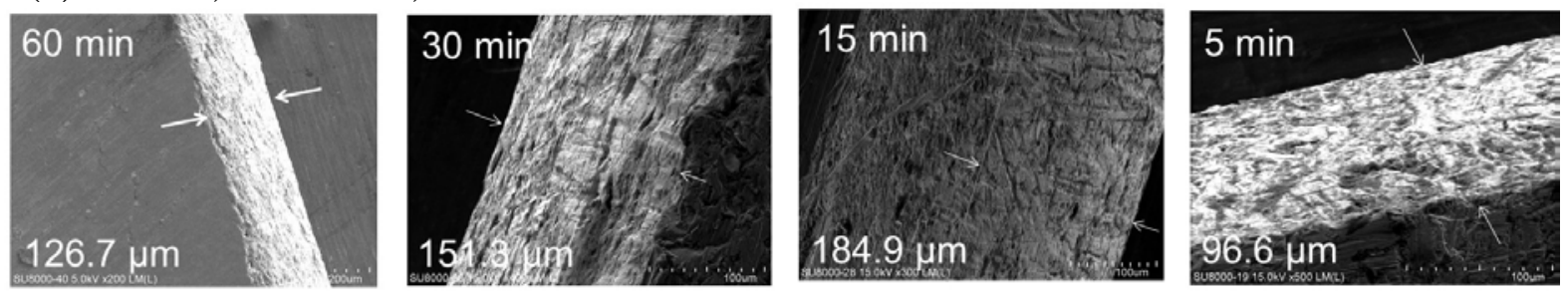

(c). $200{ }^{\circ} \mathrm{C} ; 5 \mathrm{~min} ; 0.1 \mathrm{~A} / \mathrm{cm}^{2}$
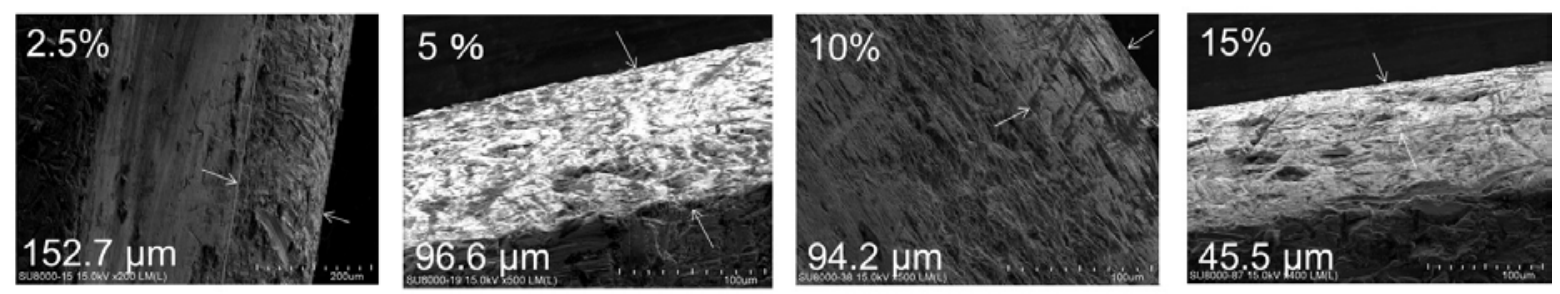

(d). $200{ }^{\circ} \mathrm{C} ; 5 \mathrm{~min} ; 5 \% \mathrm{NaOH}$
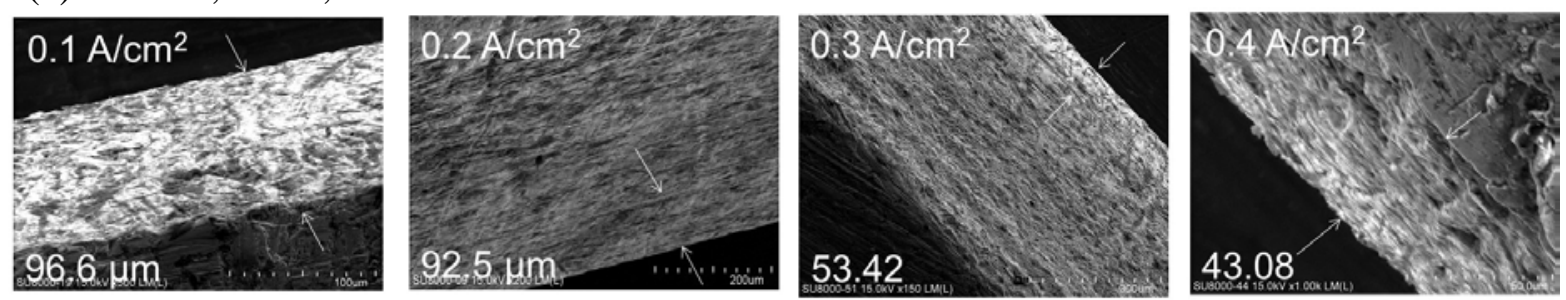
Fig. 6. Cyclic voltammograms obtained for mild steel before and after treatment by hydrothermal or hydrothermal electrolysis.

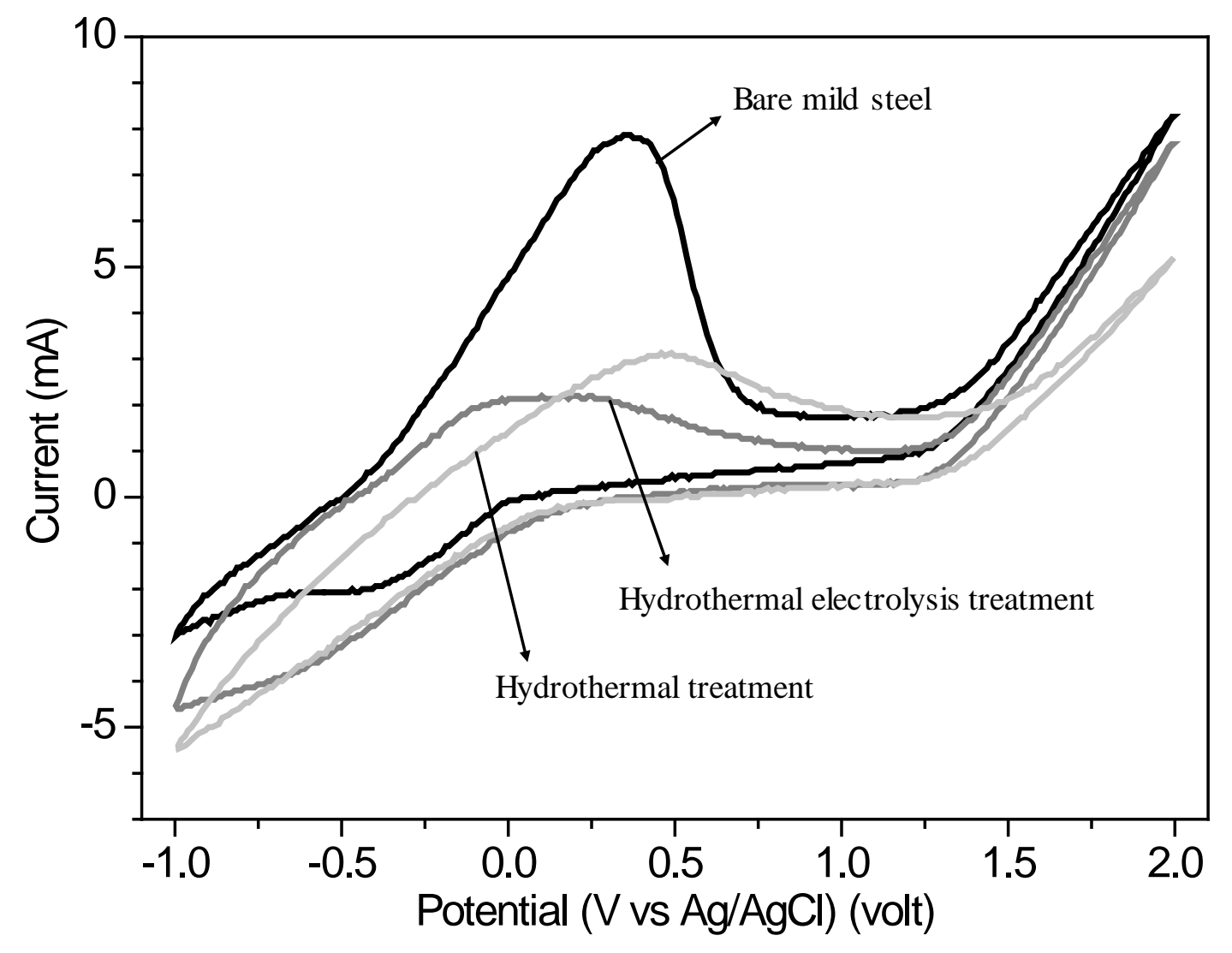


Fig. 7. SEM images of mild steel surface after anodizing by hydrothermal electrolys is at (a). 160 ${ }^{\circ} \mathrm{C}$ and (b). $200{ }^{\circ} \mathrm{C}$, respectively.
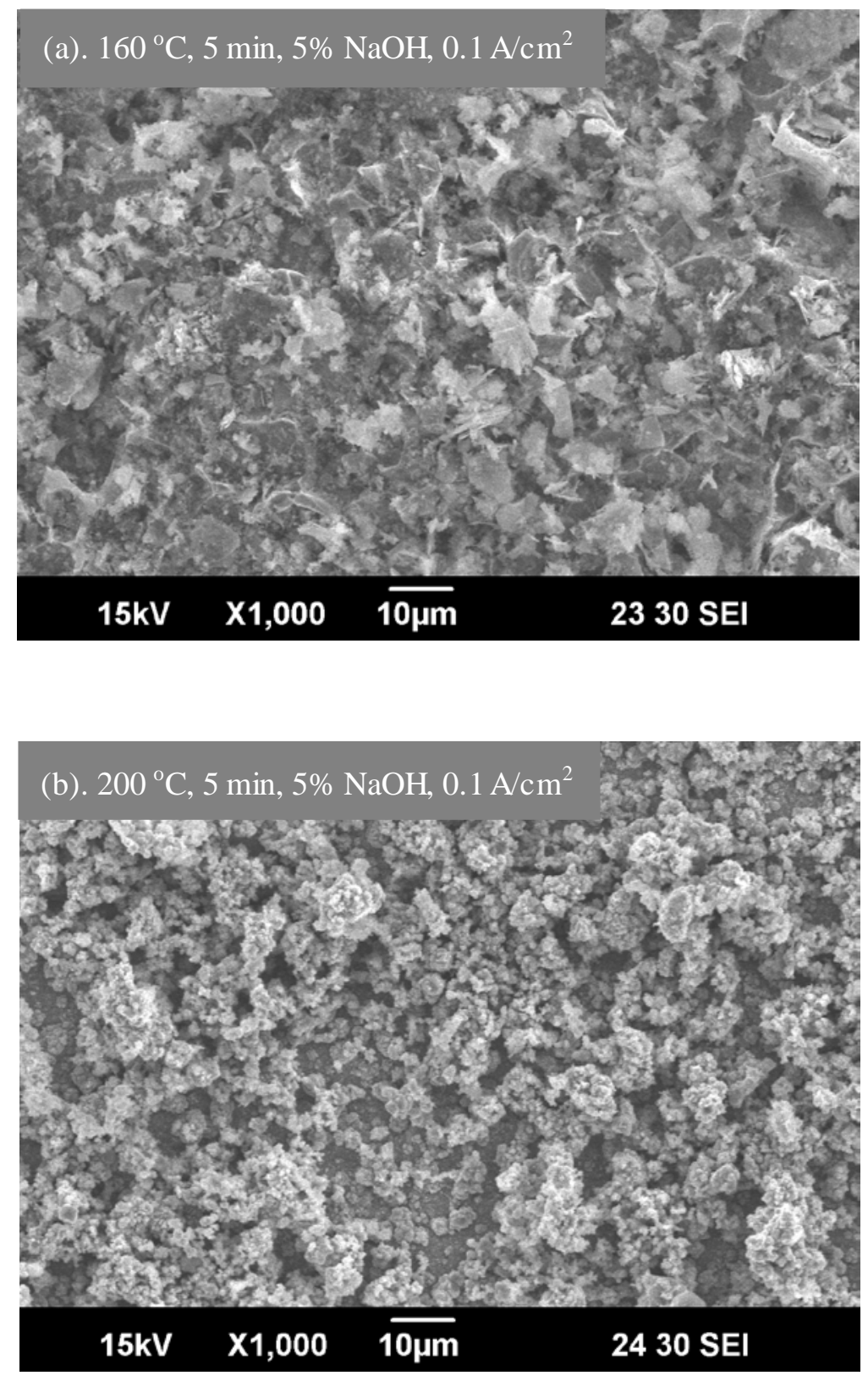